bush lamps (6) empty drums, etc. None of the aforementioned is ideal to warn road users. Crashes becomes inevitable when night falls. The greater number of casualties in Nigeria is as a result of rear impact to stalled trucks and articulated vehicles. This has led to multiple death of innocent road users. Our photographs highlight one of the hidden causes of road death in LMIC. You will see pictures of the described scenarios and that of the victims. We have had 1, 2, 5 18, 45, 70 death at once due to poor visibility of obstructions on the highways. Before we begin the decade of action (2011-2020), if LMIC works on enhanced visibility, we would cut down road death by about $45 \%$. The concluding part will show pictures of how the advanced countries curbed the menace. The LMIC should copy best practices.

\title{
1024 THE DANGER OF POOR VISIBILITY
}

P Adenusi* Correspondence to EL-ELYON (Valu4life), 49 Bamgbose Street, Lagos Island PO Box 73436, Victoria Island Lagos 234NG, Nigeria

\subsection{6/ip.2010.029215.1024}

The growing trend of road crashes all over the world has become a major concern to all. Over the years emphasis has been on speed, seat belt, tyres, road conditions, etc. The low/ middle income countries (LMIC) contribute the larger number of casualties. There is a major disconnect of attributing some cases to speed rather than poor visibility. In the LMIC, about $90 \%$ of heavy goods vehicles does not have retro-reflective tape fixed to their trucks. On several occasions, the trucks breakdown and what is used as warning signs to warn other road users are: (1) leaves (2) used tyres (3) wood (4) stones (5) 